\title{
Smart Mall Shopping Submitted to International Journal of Scientific and Research Publications
}

\author{
Mayuri Sonawane, Swati Pawar, Aditi Abhang, Vaishali Khandave \\ Department of Computer Engineering, University of Pune, \\ MET's Instituate of Engineering, Aadgaon, Nashik, Maharashtra, India
}

\begin{abstract}
How to cite this paper: Mayuri Sonawane | Swati Pawar | Aditi Abhang | Vaishali Khandave "Smart Mall Shopping Submitted to International Journal of Scientific and Research Publications" Published in International Journal of Trend in Scientific Research and Development (ijtsrd), ISSN: 24566470, Volume-3 | Issue-3, April 2019, pp.813-814, URL: https://www.ijtsrd.c om/papers/ijtsrd23 045.pdf

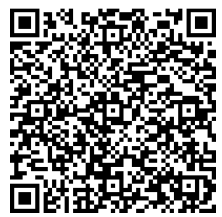

IITSRD23045

Copyright (C) 2019 by author(s) and International Journal of Trend in Scientific Research and Development Journal. This is an Open Access article distributed under the terms of the Creative Commons

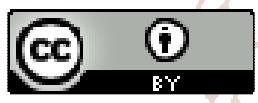
Attribution License (CC BY 4.0) (http://creativecommons.org/licenses/ by $/ 4.0$ )
\end{abstract}

\section{ABSTRACT}

A product having societal acceptance is the one that helps comfort, provides efficiency and convenience in everyday life. Big shopping complexes are being developed in metro cities. Huge rush can be seen at these malls on holidays and weekends. People wanting to purchase products have to carry them in the trolleys. After finishing choosing the products, one proceeds to go to billing counter. At billing counter bill is generated by scanning the products manually using a hand assisted barcode scanner. This takes a lot of time resulting in a long queue for billing. In this project, we discuss a system which is being developed to aid a person in day-to-day shopping in terms of reduced time spent while purchasing. The main objective of proposed system is to provide a technologyoriented approach which is pocket friendly, scalable and rugged system for assisting shopping. Key Words: Intelligent Shopping, Shop-ping Cart, User Interface, Server Communication, Automatic billing.

\section{INTRODUCTION}

This system will assist customer in his everyday shopping by reducing the shop- ping time. It also provides better assistance to the mall managers. This is an innovative system that will provide comfort and convenience to the shoppers and managers. While surveying we found that most of the people prefer to leave the shopping mall instead of waiting in long queues to buy a few products. People find it difficult to locate the product they wanted to buy, after selecting product they need to stand in a long queue for billing and payment. To try to solve the problems previously identified, we have developed our system. Another motivation is the use of smart-phone for implementing shopping in shopping malls using better interface for users and to ease the process. To provide a technological view to solving the problem of manual shopping systems in malls.

\section{OVERVIEW}

According to present scenario. Now a days shopping at big malls is becoming a daily activity in metro cities. The huge rush at the malls on holidays and weekends. After purchase, at a billing counter the cashier prepare the bill using bar code reader which is a time consuming process and results in long queues. Considering all this, we have implemented a system that can be used in shopping malls to solve the rush at billing counter using Smart Mall System.

\section{LITERATURE SURVEY}

Shopping malls today are increasing in dimension with more goods and variety of wares due to improved living standards resulting to pursuit of high quality consumer goods, which in turn reveals the demand for efficient shop-ping processes. According to, a similar trend exists for the online shopping system at even a greater pace than the traditional shopping malls. However, they also come with a number of laws, thereby restrictive the objectives of electronic shopping. Some of the major problems faced could include security, fraud and more often, delay in delivery of orders. The objective of this project is to propose a real time capturing system for consumer supplies using Quick Response (QR) code in an Android smart phone. In recent years, valuable research has been carried out on vision-based automatic identification technology that recognizes image codes using smart phones to provide various services that can recognize the authenticity of any product. (disadvantage-Bar code not scanned properly). 


\section{PROBLEM DEFINATION}

A number of shopping websites online offer large number of products to meet the shopping interest of large number of customers. Basic problems with the existing systems are that they have non-interactive environment. Use of such laidback user interface makes frequent posts back to the server to display results causing delay. The existing system results in too much rush in the mall while handling products and the space in mall. Existing System provides no detailed records of all users. It is inconvenient for the customers to carry all purchased products and look other products.

\section{A. Need of Smart Mall Shopping}

As we have seen that customers are facing a lot problems nowadays of time consumption and overall complexity, by using these software we lower the issues that customer are facing that customer take plenty of time to select any product but while billing it takes more time than purchasing because the bar code that are label are not scanned properly due to distance problem that s why we use QR code i.e (Quick response) which will scanned by not only by billing boy but by the ordinary user as well. All he need to do is scan the QR code by software or customer can scan by daily software as well. Half part being reduced of scanning the code which will be scanned by customer. Again no need to carry heavy cart which disturbs other customer as well simply carry your phone and connect to packing boy and billing boy which will carry your heavy cart any you can do freely shopping which we all want.

\section{ADVANCE ENCRYPTION STANDARD(AES)}

It is a symmetric encryption Standard algorithm.128-bit group encryption with 128,192 and 256-bit key length. Symmetric algorithm requiring only one encryption and decryption key. There are Various Steps like 1.Byte Substitution(Sub Bytes) 2.Shift Rows 3.Mix Columns 4.AddRound Key And Same for the Description process.

\section{QR- CODE GENERATION}

QR codes, on the other hand, can not only hold 100 times more data than 1D barcodes they can also be digitally scanned. The three large squares act as alignment targets, while the smaller square in the remaining corner acts to normalize the size and angle of the shot. The blue strips near the alignment squares contain formatting information, and the remaining yellow area is the actual data that's converted into binary code and checked for errors before being displayed. The encoded data can be interpreted as one of four primary modes numeric, alphanumeric, byte/binary, and Kanji. Other forms of data can also be displayed with the appropriate extensions.

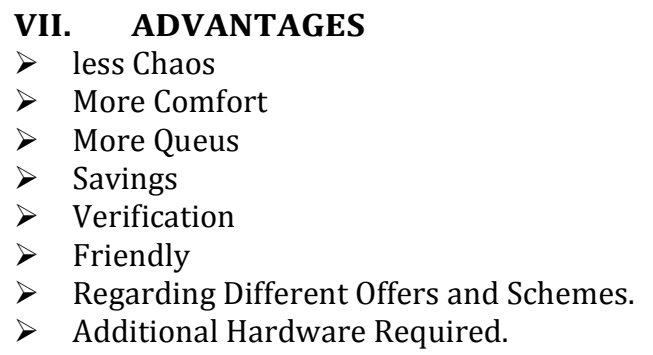

\section{FUTURE SCOPE}

The proposed Smart Shopping mall System intends to as-sis shopping in person which will minimize the considerable amount of time spent in shopping as well as to time required in locating the desired product with ease. The customer just needs to type the name of the product he wants to search on the Android device, and the cart will automatically guide him/her to the products locations.

\section{CONCLUSION}

The proposed system is helpful to both user and mall managers. The system is developed considering all issues related to all users included. Variety of customers can use this system if they know how to operate android smart phones. System is user friendly, low-cost and does not need any special training. Our system would prove time saving and ease the shopping process for many people using the system. The advantages of the system make it more robust.

\section{APPENDIX}

Intelligent Shopping: defined as a tendency for consumers to invest considerable time and effort in seeking and utilizing promotion related information to achieve price savings. References are important to the reader; therefore, each citation must be complete and correct. If at all possible, references should be commonly available publications.

\section{CONCLUSIONS}

A conclusion section is not required. Although a conclusion may review the main points of the paper, do not replicate the abstract as the conclusion. A conclusion might elaborate on the importance of the work or suggest applications and extensions.

\section{REFERENCES}

[1] G. Venkatachalam, QR Code Generation for Mall Shopping Guide System with Security Asian Journal of Applied Science and Technology (AJAST), may 2017.

[2] Raju Kumar , K. Gopalakrishna, K. Ramesha, Shopping with cart, International Journal of Engineering Science and Innova- tive Technology (IJESIT) ISSN: 2319-5967 Volume 2, Issue 4, July 2013.

[3] W. Wang, A. X. Liu, M. Shahzad, K. Ling, and S. Lu, A Fully Functional Shopping Mall Application SHOPPING EYE, in Proc.ACM MobiCom, Sep. 2015, pp. 6576.

[4] Hsin-Han Chiang, Shopping Assistance and Information Pro- viding Integrated in a Robotic Shopping Cart 2017 IEEE International Conference on Consumer Electronics - Taiwan (ICCE- TW).

[5] Megha R. Mane, Electronic Shopping Using Barcode Scanner 2015 International Conference on Science in Information Technology (ICSI Tech).

[6] Mr. Jayesh B Mahajan, Mall Shopping System Using NFC Inter-national Journal of Scientic and Research Publications, Volume 5, Issue 11, November 2015

[7] D. Wright, The dark side of ambient intelligence, info, vol. 7, no. 6,pp. 3351, 2015 ..

[8] H. Krawczyk, M. Bellare, and R. Canetti, Hmac: Keyedhashing for message authentication, in RFC 2104, 2015.

[9] Raju Kumar , K. Gopalakrishna, K. Ramesha, Shopping with cart, International Journal of Engineering Science and Innova- tive Technology (IJESIT) ISSN: 2319- 5967 Volume 2, Issue 4, July 2013. 